\title{
Aspects of Professional Collaboration in a Lesson Study
}

\author{
Adriana Richit ${ }^{1,2 \star ~(D), ~ J o a ̃ o ~ P e d r o ~ d a ~ P o n t e ~}{ }^{2}$ (i), Ana Paula Tomasi ${ }^{3}$ (D)
}

${ }^{1}$ Universidade Federal da Fronteira Sul - UFFS, BRAZIL

${ }^{2}$ Instituto de Educação, Universidade de Lisboa, PORTUGAL

${ }^{3}$ Universidade Federal da Fronteira Sul - UFFS, BRAZIL

*Corresponding Author: adriana.richit@uffs.edu.br

Citation: Richit, A., Ponte, J. P., \& Tomasi, A. P. (2021). Aspects of Professional Collaboration in a Lesson Study. International Electronic Journal of Mathematics Education, 16(2), em0637. https://doi.org/10.29333/iejme/10904

ARTICLE INFO

Received: 8 Nov. 2020

Accepted: 17 Jan. 2021

\begin{abstract}
We examine aspects of professional collaboration in a lesson study conducted with mathematics teachers from the final years of basic education belonging to public schools in the State of Rio Grande do Sul, Brazil. The lesson study, conceived as a professional development approach focused on collaboration and reflection, took place in the 2 nd semester of the 2019 school year, organized in 12 meetings of 2.5 hours each, and involved 8 tenured teachers in schools belonging to the 15th Regional Education Coordination of that State. The empirical material of the study consisted of the field notes produced at each meeting of the lesson study, the data from an initial questionnaire administered to the teachers, as well as the transcription of the audio recordings of the interviews with the participants and of the sessions of the lesson study. The qualitative and interpretative analysis showed that the dynamics of the lesson study enhanced several basic aspects of collaboration, namely mutual encouragement and support, cooperation and shared reflection.
\end{abstract}

Keywords: professional collaboration, lesson study, professional development, professional culture

\section{INTRODUCTION}

Professional collaboration, a specific kind of collaboration concerning professional issues, is currently an emerging theme in education, especially in mathematics education. It may be "understood as an ideal way to ensure the professional development of teachers throughout their careers, pupils' learning ... and the transformation of schools into authentic learning communities" (Lima, 2002, p. 7). The concept of collaboration emerged at the turn of the century as a metaparadigm of change in the educational and organizational spheres (Hargreaves, 1998), and is therefore not a novelty in the discussions on teacher education within the scientific community of education. However, interest in this theme has recently gained a new impetus both within the scope of research and in the implementation of actions supported by collaborative features, due to its potential for promoting change in face of the challenges presented by contemporary education.

Evidence of the growing interest in this theme may be observed in the actions promoted by the International Commission on Mathematical Instruction (ICMI). This Commission promoted the ICMI Study 25 meeting, in Lisbon, Portugal, in February 2020, with the theme "Teachers of Mathematics Working and Learning in Collaborative Groups", which sought to investigate different forms of professional collaboration. In the meeting, approximately 80 papers were presented on this theme, signed by researchers from countries in every continent of the world. The interest taken in professional collaboration in the field of mathematics education points to the increased importance given to this perspective of professional development and heralds the emergence of new research objects within the scope of this theme.

Along with the discussion on professional collaboration within the mathematics education research community, an important theme has gained prominence, namely lesson study, grounded in the basic features of collaboration and reflection. Originating in Japan at the turn of the $20^{\text {th }}$ century, lesson study was consolidated as one of the main processes of teachers' professional development in that country (Lewis, 2002), stemming from the transition from an individualized instruction model to a mutual instruction model in the early $21^{\text {th }}$ century (Isoda, 2007; Richit, 2020).

The discussion and research on lesson study and professional collaboration paved the way for the emergence of yet another new research theme (Richit, Ponte \& Tomkelski, 2020), more specifically, professional collaboration in lesson study, addressing the way how teachers work and develop professionally in a lesson study. It was in this field that we conducted research seeking to examine collaboration in lesson study from the perspective of teachers of basic education in Lisbon (Richit \& Ponte, 2019). However, upon realization of the central role of collaboration in lesson study, we decided to extend our research of this professional dimension to the Brazilian context, in which the school culture of the education system is strongly characterized by professional isolation (Richit \& Tomkelski, 2020). 
Thus, we conducted research on professional collaboration in a lesson study with mathematics teachers in the final years of basic education within the public network of Rio Grande do Sul, seeking to identify the basic feature of collaboration experienced in this process (Tomasi, 2020). On the basis of this research, and having noted the lack of depth in the general approach to the study of professional collaboration in lesson study, we undertook this research aiming to highlight the features of collaboration that play a fundamental role in this domain. The study aimed to answer the following question: What are aspects of professional collaboration essential for teacher professional development in a lesson study? The analysis was guided by two sub-questions: How is professional collaboration enacted in lesson study? What are the characteristics of professional collaboration evidenced by participating teachers?

The relevance of this analysis lies in the fact that it may indicate paths for lesson study in environments marked by professional isolation, giving teachers the opportunity to attain collaboration in teacher education and professional practices, thereby enhancing their professional development. Therefore, this paper may contribute to deepen the discussions concerning teacher professional collaboration, especially in lesson study contexts, highlighting collaboration aspects that favor teacher professional development.

\section{TEACHERS' PROFESSIONAL DEVELOPMENT AND COLLABORATION}

\section{Professional Development Dimensions}

Teachers' professional development involves fundamental dimensions, such as the constitution of basic knowledge for teaching, professional career development, professional learning, assimilation and modification of professional culture, changes in practice and political and contextual conditions of the teaching profession. Conceived as such, professional development characterizes the set of systematic efforts taken to promote changes in the practices of teachers in the classroom, in their attitudes and beliefs and in the learning outcomes of pupils (Guskey, 1997; Guskey \& Huberman, 1995).

In a study on the challenges of teachers' continuing professional learning, Day (2001) presents a broader concept of professional development, which includes the perspective of professional development intrinsic to lesson study. According to this author, professional development involves spontaneous teacher learning experiences as well as activities that are planned and implemented for individual and group growth, which foster changes in the quality of teaching in the classroom. Furthermore, it characterizes the process

by which teachers, as agents of change, review, renew and expand, individually or collectively, their commitment to the moral purposes of education, acquire and develop, critically, along with children, young people and fellow teachers, knowledge, skills and emotional intelligence, essential for effective professional reflection, planning and practice in each stage of their working lives (Day, 2001, p. 20).

The concept presented by Day (2001) demonstrates the timeless, dialectic, dynamic and socio-historical nature of teachers' professional development and relies on the initial and continuous teacher education of teachers as its main device (Roldão, 2007). Therefore, it involves initial teacher education, the daily professional activities of teachers, their personal characteristics and experiences, their beliefs and dispositions, elements of the professional culture, various teacher education devices experienced throughout their careers (frequency of courses and events, socialization of experiences and reflection on teaching, participation in teacher associations), professional learning achieved, personal and professional growth, as well as teachers' openness to change in practice. However, in Guskey's (2002) view, these changes are influenced by teachers' attitudes and beliefs which, in turn, are shaped by their context and daily professional experience.

The perspective of Guskey (2002) therefore circumscribes elements that are present in school cultures, such as the way in which professionals relate to each other, how they perceive each other and interact in the professional context, how they make curriculum and didactic decisions (Day, 2001). In addition, it involves how they react to unexpected situations, how they are encouraged to experiment changes in practice and how they constitute themselves as education professionals. Day (2001) systematizes these features in three broad dimensions of professional development: basic knowledge and skills for teaching; developing a new understanding of oneself; and ecological change, involving aspects of the context and culture.

In the same vein, in their examination of the influence of professional culture on teachers' professional growth, Saraiva and Ponte (2003) stress that teachers, both individually and as peers

review, renew and expand their commitment to the purposes of education and acquire and develop, critically, the knowledge, techniques and intelligence (cognitive and affective) that are essential to quality professional practice with their pupils in the school setting. (p. 27)

By the same token, Lima (2002) examines the structures, processes and contents of collaborative cultures in schools, highlighting that "the professional cultures of teachers represent more than simple aggregates of knowledge and concepts: they also integrate behaviours and practices, ways of acting in schools and interacting with fellow teachers" (p. 51).

In view of these understandings, the professional cultures of teachers need to be understood in terms of beliefs, values, behaviours and practices, taking "doing and acting" and "feeling and thinking" into consideration (Lima, 2002). In addition, they need to be understood 
not only as sets of values, representations and norms, but also as consistent and relatively regular forms of action and interaction patterns that teachers internalize, produce and reproduce during (and as a result of) their work experiences. (Lima, 2002, p. 20, original italics)

This perspective is supported by the ideas of Hargreaves (1998), according to which teachers' professional cultures are grounded in human relationships, since this perspective is based on the assumption that there is a shared culture in every organization. According to the author, a culture rooted in relationships "highlights that which is privately held and shared in human relationships: values, habits, norms and beliefs, that is, the shared content of teachers' cultures" (Hargreaves, 1998, p. 213). A deepening of the concepts of culture and professional culture leads to the characterization of four types of teacher culture: individualism, contrived-collegiality, balkanization and collaboration, the latter being the focus of analysis in this paper.

\section{Teacher Professional Collaboration}

The culture of collaboration, taken as a fundamental dimension of professional development that characterizes the predominant ways of being, acting and thinking in learning communities consisting of teachers (Day, 2001), takes as its point of departure peer dialogue, interaction with fellow workers, decision-making and mutual support (Hargreaves, 1998). Through collaboration, teachers are encouraged to diversify their teaching strategies, take risks, face changes, reflect on their own practice, thus attaining the level of professional growth that provides the opportunity for educational change (Hargreaves, 1998). Therefore, collaboration is not an end in itself but rather a means to achieving another end, namely teachers' professional development. According to Hargreaves (1998), this development is fostered "beyond personal and idiosyncratic reflection or dependence in relation to external experts, leading to teachers' learning from each other and to sharing and developing their skills together" ( $p$. 209).

Thus, based on Hargreaves' pioneering professional collaboration studies, important features related to this concept have been researched, developed and systematized in scientific communities of education, such as dialogue, sharing, negotiation, group work, cooperation, mutual help, etc. Among the different features intrinsic to collaboration, mutual encouragement and support, cooperation, and reflection are of particular relevance.

Mutual encouragement and support has been identified as one of the main elements of professional collaboration in educational contexts (Day, 2001; Lima, 2002; Roldão, 2006), since it constitutes a condition for participants in a learning community to feel part of a group (Borges, 2007) and to feel driven to take more risks (Guskey \& Huberman, 1995), while serving as positive or negative support for teachers' professional learning (Day, 2001). Roldão (2007) also underlines this feature by emphasizing a number of theoretical domains that support collaborative work, such as "its relational and ethical value" (p. 25). Furthermore, she states that collaborative work is a way of fostering educational changes, especially within the dimension of teachers' work, based on good relationships and openness towards others.

In a similar sense, when examining the ways of being a teacher in Portuguese schools, Borges (2007) points to the need to understand contradictory elements in this process. She highlights that mutual help and support has been a central feature in teachers' relationships, contributing to an enhancement of the value of members as individuals and of the group to which they belong. From a complementary perspective, Feixas (2004) examines the personal, institutional and contextual factors that influence the professional development of teachers (especially university teachers) and concludes that this process is not linear, but permeated by advances and setbacks. She also highlights how support among peers in the same area, or who teach the same subject or work in the same contexts impacts teachers' practice in different ways, according to where they are in the career cycle. The author concludes that not only the most experienced and confident teachers who collaborate in orientations and decisions as also the youngest and most motivated teachers, who share their ideas with potential for innovation, contribute to the professional development of teachers in both individual and collective dimensions. In addition, Boavida and Ponte (2002) consider that collaboration, as a professional development lever, even when stimulated by a facilitator, presupposes an attitude of openness and trust among participants to the benefit of all.

Cooperation characterizes the first step towards collaboration, where participants become part of the process, take on a degree of responsibility and perform a task. When examining the implications of cooperation in collaborative cultures, Thurler (2001) characterizes this feature as an essential element for educational change. It is comprised of a set of professional practices carried out cooperatively, such as team teaching, collective planning, research-action, lasting companionship and coaching. She adds that over time, these practices strengthen interdependence within the group, the division of responsibilities, collective engagement and openness to self-assessment and self-criticism, thus fostering collaboration. However, she emphasizes that when cooperation practices are carried out in isolation, they do not foster collaboration, as the latter is based on the assumption of shared values and tasks, commitment and prolonged involvement.

According to Day (1999), cooperation is distinguished from collaboration in the way personal and power relationships occur among the members of a given group. In purely cooperative groups, power relations and the roles of participants are not questioned, while collaborative relationships require careful negotiation, joint decision-making, effective communication and mutual learning in a venture characterized by the promotion of professional dialogue. Hence, "cooperation among a collaborative group is permeated by other elements, particularly support, dialogue and negotiation" (Richit \& Ponte, 2019, p. 941).

Reflection, which consists of "asking oneself what is happening or what is going to happen, what can be done, what should be done" (Perrenoud, 2002, p. 30), has proven to be an important feature of collaboration, albeit understated in studies related to the theme of 'professional collaboration in lesson study', as well as in studies concerning other professional communities.

Among the works that highlight reflection as an element of collaboration, in which it manifests itself intertwined with other elements, Saraiva and Ponte (2003) observe that a collaboration culture fosters educational change insofar as it involves the 
transformation of values, attitudes, emotions and perceptions that guide teachers' practice. However, the authors stress that this change is only possible if teachers have a support base among their peers, providing them with the support to deal with "the anxieties that accompany the difficulties inherent to change" and, above all, if they are given the time and conditions to reflect on this process and its requirements (Saraiva \& Ponte, 2003, p. 30). In addition, Roldão (2007) states that reflection, the joint analysis of teachers' actions, as well as collaborative research that promotes professional knowledge are results of a constant teacher education process in the teaching activity.

In their studies on teachers' professional development, Guskey and Huberman (1995) point to several factors that permeate this process, including reflection on practice. According to these authors, by reflecting on their own practice, observing and analysing the practice of fellow teachers and examining case examples of other practices, teachers can clarify the dilemmas they face on a daily basis and develop principles, practices, skills and reflected ways of dealing with these dilemmas. In the same vein, Roldão (2007) considers collaborative work to be structured in articulated, reflected work, that is thought through jointly, and based on the dynamic interaction of those involved.

In short, collaboration fosters professional development insofar as it provides the opportunity for teachers to work together, "providing mutual support, offering constructive feedback, developing common goals and establishing limits that present challenges (but which are realistic at the same time) regarding what can be reasonably accomplished" (Hargreaves, 1998, p. 19).

According to Guskey and Huberman (1995), professional development can help create working conditions and foster collaborative cultures, in which teachers, together, can develop, clarify, review, reflect on and redefine their purposes, missions and points of view. Through joint discussion, as team partners, their own fellow teachers can serve as mirrors for teachers to look at their own practices. Teachers may also have or position themselves as "critical friends", willing to talk to their peers, to observe them, give them feedback, offer another perspective, provide access to reading material and research, leading them to deeply and critically question the moral foundations and consequences of their actions in the classroom (Guskey \& Huberman, 1995).

\section{LESSON STUDY}

Lesson study, a professional development approach centered around collaboration and reflection (Lewis, 2002; Murata, 2011), involves small groups of teachers, who work collaboratively on the basis of four main stages: identifying a learning problem and formulating goals for pupil learning; preparatory work and planning a lesson for a class of pupils (the research lesson); teaching this class while being observed by a team of teachers and researchers; and reflecting on the aspects of pupils' learning observed by the team (Richit \& Ponte, 2019). Throughout this process, teachers collaboratively and reflectively accomplish articulation between theory and practice, thereby constituting new teaching professionalism attributes in mathematics education (Richit, 2020).

When formulating objectives for pupils' learning and development, a topic or theme of the curriculum is selected to be further explored in the lesson study and pupils' main difficulties in that topic are analysed; in the planning stage, the research lesson is carefully prepared to achieve the defined objectives, taking into account pupils' frequent difficulties in that topic; when teaching the research lesson to a class of pupils, the observers collect information on the pupils' actions during the class, through notes or audio or video recordings; in the reflection stage, the aspects observed and recorded during the lesson related to the pupils' learning and development are carefully analysed and discussed, giving teachers the opportunity to understand the pupils' learning, difficulties and reasoning processes. Based on these features, the lesson may be improved (Richit, Ponte \& Tomkelski, 2019).

As far as collaboration is concerned, research has suggested that lesson study enables participants to carry out collaborative work and experience a new classroom practice (Ponte et al., 2016; Richit \& Ponte, 2020). It also allows teachers, in their professional practices, to develop collaborative work through the sharing of objectives, the discussion of ideas and the joint development of teaching resources (Burroughs \& Luebeck, 2010). Moreover, it provides opportunities for participants to overcome the professional individualism that is prevalent in teachers' daily lives, as well as fostering opportunities to experience different collaborative forms of professional learning (Richit \& Tomkelski, 2020). In addition, Ponte et al. (2016) highlight that lesson study, due to its collaborative features, emerges as a context to promote communication processes among participants and reflection on professional practice, and thus has come to be viewed as an important channel for the promotion of mathematics teachers' professional development.

Reflection, according to Lee (2008), can foster "the development of more sophisticated conceptions of teaching and the learning process" (p. 117) and, thus, promotes teachers' professional development. The author postulates that reflection may reveal itself at three levels, and is "examined in terms of the depth of the thinking process involved" (Lee, 2008, p. 120). The first level of reflection is "recall", which refers to the way a problem or situation is described and interpreted, without looking for alternative explanations. The second level of reflection is "rationalization", in which the problem or situation is interpreted with reasoning, with guiding principles, through relationships. The third level refers to "reflectivity", which addresses one's own experiences from a perspective of change (Lee, 2008, p. 120). The author concludes that reflective thinking is distinguished from the lowest to the highest level, which involves a deeper thought process with regard to the interpretation of a problem, as well as the ability to question and explore the problem's different reasoning and alternatives, thus promoting changes in practice (Lee, 2008).

Therefore, lesson study, due to its development and purpose dynamics, is based on and promotes collaboration and reflection as teachers work together, cooperating and supporting each other, while simultaneously being able to look at the practice of others while exposing their own. Thus, teachers expand their knowledge and reassess their professional beliefs and dispositions, 
Table 1. Brief description of the lesson study

\begin{tabular}{ll}
\hline Meeting & Activities \\
\hline First meeting & $\begin{array}{l}\text { The facilitators presented the teacher education proposal, explaining the objectives and stages. They then exposed the } \\
\text { historical and theoretical features of lesson study, the development structure and dynamics of the approach and the focus of } \\
\text { the process on pupil learning. Finally, the teachers were involved in defining the curriculum topic to be addressed (they } \\
\text { decided "area and perimeter of flat figures"), identified the main pupils' difficulties in this topic and defined objectives for the } \\
\text { research lesson, taking those difficulties into account. }\end{array}$ \\
\hline $\begin{array}{l}\text { Second } \\
\text { meeting }\end{array}$ & $\begin{array}{l}\text { The facilitators presented features of lesson study that promote teachers' professional development in mathematics } \\
\text { education. The participants discussed in detail pupils' difficulties in the topic of area and perimeter. }\end{array}$ \\
\hline meeting & $\begin{array}{l}\text { The teachers worked on planning two research lessons on the chosen topic, seeking to gear the pupils towards overcoming } \\
\text { their most frequent difficulties. Readings and discussions on the origin and dynamics of the development of lesson study were } \\
\text { carried out, with a more in-depth analysis of area and perimeter and the main results of the research on lesson study and on } \\
\text { the teaching and learning of this curriculum topic. }\end{array}$ \\
\hline $\begin{array}{l}\text { Ninth to twelfth } \\
\text { meeting }\end{array}$ & $\begin{array}{l}\text { The last four meetings corresponded to two research lessons followed by reflection, which were organized as follows: in the } 9^{\text {th }} \\
\text { meeting, research lesson } 1 \text { was taught and in the following (10 } \\
\text { based on the notes produced by the observers. The same approach was adopted in relation to research lesson } 2, \text { taught in the } \\
\text { penultimate meeting. Each lesson was taught voluntarily by a different teacher and in a different } 8^{\text {th }} \text { year class. In the } 12^{\text {th }} \\
\text { meeting, a general evaluation of the lesson study was also carried out. }\end{array}$ \\
\hline
\end{tabular}

leading to changes in practice. In this perspective, this paper may contribute to deepen the discussions concerning to teacher professional collaboration, highlighting aspects of collaboration that may favor teacher professional development.

\section{METHODOLOGY}

\section{Context, Participants and Data Collection}

This paper aims answer the question "What are aspects of professional collaboration essential for teacher professional development in a lesson study?" The analysis of empirical material was guided by two sub-questions: How is professional collaboration enacted in lesson study? What are professional characteristics of collaboration evidenced by participating teachers?

The research was conducted within the scope of teacher education initiatives carried out by the Grupo de Estudo e Pesquisa em Educação Matemática e Tecnologias (GEPEM@T) [Study and Research Group on Mathematics Education and Technologies] in partnership with the $15^{\text {th }}$ Regional Coordination of Education (CRE), a management body linked to the State Education Department of Rio Grande do Sul, Brazil. The participating teachers (six women and two men) are mathematics graduates and have between five and twenty years of professional experience. Its specific focus was a lesson study developed in the $2^{\text {nd }}$ academic semester of 2019, involving eight mathematics teachers of the final years of basic education (years 7 to 9). The duration of the lesson study was from August to December, and it was organized in twelve 2.5-hour meetings (Table 1). The lesson study meetings were held in a physical space provided by the $15^{\text {th }} \mathrm{CRE}$, while the research lesson ( $3^{\text {rd }}$ stage of the lesson study) was held at the school of origin of the teacher who taught this lesson.

The empirical material of the study consisted of field notes produced throughout the lesson study sessions; reports drawn up after each session, in which the dynamics of the meeting and the interactions among the participants were detailed; data resulting from an initial questionnaire applied to the teachers, through which information on their teacher education and professional experience and their expectations related to lesson study were sought; transcripts of audio recordings of all the meetings; and transcripts of the interviews carried out with the participants after the lesson study (carried out in June 2020), in which they were asked to talk about their experience, the lessons learned and, particularly, about any remarkable aspects of collaboration throughout the process.

\section{Data Analysis Framework}

The empirical material was organised according to the different sources of data (field notes, reports, questionnaire, interviews etc.). Then, using content analysis (Bardin, 2003), we made a floating reading of this material, through which we identified different situations that characterise aspects of professional collaboration in lesson study. These situations were grouped according to the convergence between them, constituting the categories of analysis of the study, that is, the main aspects of professional collaboration mobilized in the lesson study according to the perspective of the participating teachers. Finally, the empirical evidences associated with each category of analysis (encouragement and mutual support, cooperation, and shared reflection) were interpreted and discussed seeking to identify the basic features of collaboration experienced in this process.

\section{LESSON STUDY}

\section{Global Analysis}

A global analysis of the lesson study points to a high degree of involvement and participation of the teachers in all the sessions. All teachers were present in over $90 \%$ of the lesson study sessions, with only one teacher not participating in a planning session and one teacher not observing a research lesson. 
One of the striking aspects at the beginning of the lesson study was the concern shown by the teachers regarding the choice of the topic that would be worked on with the pupils, as well as the selection of the class for the research lesson (third stage of the lesson study). The group displayed considerable concern at this level as the teachers carefully discussed and reflected on the need to think about the definition of the topic from the contents already addressed in the classroom, which are fundamental for understanding the proposed activity.

Through a context of dialogue and decision negotiation, the teachers reported professional experiences on different curriculum topics in mathematics in the final years of basic education and discussed pupils' main learning difficulties in those topics. Besides, they aimed to predict possible obstacles to the implementation of a lesson on the specified topics and suggested strategies and teaching materials that could be developed for the research lesson. Then, in this environment characterized by dialogue, the participants defined the topic to be addressed in the lesson study and the school year for which they would plan the research lesson ( $8^{\text {th }}$ year).

The planning stage of the research lesson, involving six sessions, provided teachers with moments of reflection and learning, as they read and discussed research results involving lesson study and the teaching of mathematics. Furthermore, teachers analysed the recent guidelines of the Base Nacional Comum Curricular Brasileira [National Common Core Brazilian Curriculum] for the teaching of area and perimeter in the 8th year, reflected on the approach of these topics in the main mathematics textbooks, shared experiences and reflected on teaching concepts and strategies.

During the planning of the research lesson, the teachers worked alternately in a group, including all the participants, and in two subgroups. Their task was to prepare a lesson to deal with the main learning difficulties associated with the area and perimeter of flat figures. The decision to work in two subgroups in some meetings was negotiated among the participants who considered that this dynamic would foster their mutual collaboration and deepen the discussions on the readings. They also believed that they would be able to discuss the lesson proposal in more detail in subgroups, as it was not always possible to give everyone a voice in a large group. Following their work in the two subgroups, the results of the discussions and reflections were shared in the larger group, and discussed and negotiated again. This dynamic made it possible for the teachers to improve the structure of the research lesson, to propose creative strategies for teaching the topic, taking the reality of the pupils at the schools where the research lesson would be taught. This decision also culminated in the teaching of the research lesson to two different classes of pupils, belonging to different schools. Thus, the lesson study allowed them to participate in two research lessons and reflect on the actions of pupils from two different realities.

During the planning sessions, mediation of the interactions among the participants of each group was carried out on a rotational basis, so that dialogue took on an argumentative role in relation to decision-making, thus promoting reflection on the task proposals presented by the teachers in the subgroups and in the large group. This factor highlighted the need for someone to coordinate the process, a role that circulated among the team members throughout the lesson study. The teaching stage of the research lesson, involving two classes in two different schools, enabled the teachers to carefully observe the pupils' actions in the accomplishment of the proposed tasks and also to collect information on the solving strategies and difficulties of the pupils in these tasks.

\section{ASPECTS OF PROFESSIONAL COLLABORATION BROUGHT TO LIGHT IN THE LESSON STUDY}

Based on the empirical evidence and theoretical framework of the research, some of the aspects of professional collaboration brought to light in the development of the lesson study are addressed, namely encouragement and mutual support, cooperation and shared reflection, which were most valued by the participants.

\section{Encouragement and Mutual Support}

The lesson study participants referred to the importance of encouragement and mutual support when confronted with the challenges of the school context, since encouragement and mutual support strengthened the relationships among peers and served to consolidate an effective working group. When the lesson study began, mutual support and encouragement was observed to foster the teachers' involvement in the process, which was intensified in the planning of the research lesson and in its implementation. As they encouraged each other to participate effectively in the process, especially in decision-making situations in the group, the teachers experienced a different form of professional support:

'Dire' [referring to a teacher (Ellie) who was head of the school in which she taught], say something. [Help us decide], come on, you've been in the career for years! (Maggie ${ }^{1}, 2^{\text {nd }}$ session).

In the context of the discussion on the topic addressed in the lesson study, Maggie encourages her fellow teacher (Ellie), who was the school's director that year, to participate in the discussion and report on her classroom experiences, an attitude that characterizes a form of horizontal encouragement. The encouragement motivated Ellie to share a practice in the teaching of perimeter, which was taken as a starting point in the planning of the research lesson (see the task in Figure 1). Therefore, encouragement was a fundamental aspect of collaboration in the initial stage of the lesson study.

Similarly, Judy encourages her fellow teachers to participate in the discussion and present ideas for the joint decision of the curriculum topic to be studied:

\footnotetext{
${ }^{1}$ All teacher's names are fictitious.
} 
With tangram pieces available, create one or more decorative motifs (musiva art) for the blank cards delivered to the group, using at least four (4) pieces to form the figure of each card.

Then join the cards forming a mosaic. Draw below how the mosaic turned out.

show, by drawing, the figures defined for each card.

Color/decorate the cards highlighting the outline of the figure.

Assuming we were going to decorate the outline of each figure with gold thread, how many centimetres of wire would it take? Explain your strategy.

Figure 1. Research lesson - Task 1

[Fellow teachers] we have to decide what we are going to work on. [...] let's define the topics and then move on to the second point regarding the difficulties [of the pupils] (Judy, $2^{\text {nd }}$ session).

At this decision-making moment, the teachers listened to each other in a respectful and motivated manner, emphasizing the importance of strengthening themselves as a group, reporting their teaching experiences and the challenges faced in the classroom, thus accomplishing the participation of everyone in the decision-making process (field notes, September). In addition to these aspects, the planning stage of the research lesson fostered the effective participation of the teachers, as it encouraged them to expose their ideas and accept the challenge of being involved in the process:

Initially, one of the teachers, Kadu, was quiet in the sessions and group discussions and his fellow teachers noticed this. From the third session on, it became clear that the group was making an effort to engage him, by asking him what he thought and to give his suggestions for that particular aspect. He was encouraged to give his impressions and suggestions at all times. This effort on the part of the group led to his increasing confident and active approach throughout the whole process, to such an extent that at times he even took leadership of the group and at the end taught a research lesson himself (Field notes, October).

In the case of Kadu, the support and encouragement of his peers in the planning stage of the research lesson resulted in individual confidence, which enabled him to contribute effectively to the growth of the group and to the design of the research lesson, in addition to his management of the technological resources throughout the process. This growth was consolidated when Kadu voluntarily offered to teach the research lesson in one of the $8^{\text {th }}$ year classes in which he was a teacher.

In addition, support among the peers became evident as the teachers struggled to adjust their own schedules in an attempt to benefit those with more difficulty in adapting their schedules to the lesson study timetable, especially those who were teaching in the classroom:

Since I'm not in the classroom, my timetable is more flexible. I'll speak to the head (and) will make up for it another day. The problem is for those [referring to the other teachers] who are in the classroom and have no way of leaving. (Ellie, $12^{\text {th }}$ session)

I have coordination in the morning. I can also change my morning timetable. (Judy, $12^{\text {th }}$ session)

It was possible to observe that from the first session, when the teachers had difficulty in aligning their timetables with the lesson study schedule, they supported each other and suggested adjustments that would allow them to adapt their working hours to the lesson study meetings. This support produced the conditions that enabled everyone to participate and for the lesson study to be successful.

Regarding the support and encouragement to carry out the research lesson, highly positive attitudes in this regard were noted, especially on the eve of the lesson:

There's a problem there [at school], they're going to need help. (Maggie, $10^{\text {th }}$ session).

Do you want me to go earlier to help you? (Ellie, $10^{\text {th }}$ Session).

No. It will all [referring to the lesson material] be ready [organised]. (Maggie, $10^{\text {th }}$ session).

The mutual encouragement and support benefited the way the teachers' confronted their challenges, fears, concerns and anxieties during the lesson study. In this regard, Judy states that the socialization of personal and professional experiences contributed to strengthening the support and professional encouragement among the teachers:

There was a lot of support [among the teachers [...] Seeing that the reality is the same, being able to rely on them, to be heard. Everyone was heard. We managed to share [experiences], we managed to divide problems, find better solutions. I found this sharing, this collectiveness, this conversation, this engagement really interesting and it gave me encouragement (Judy, final interview). 
For Judy, the encouragement and mutual support established trust among the peers, enabling them to find solutions for the challenges involved in conducting the lesson. Likewise, Ellie reflects on the importance of support and encouragement among fellow teachers in addressing professional challenges:

We need this support [...] we can see that the problems we face there in our school are not ours. That's generally what it is [...] So, we can see that this isn't the right way, just in my school, and that there are many challenges, and by overcoming these challenges we'll be able to make this daily practice different. (Ellie, $3^{\text {rd }}$ session)

According to Ellie, one of the challenges teachers face is working taking into account pupils' difficulties and, in her view, the solution to this challenge lies in the collaborative involvement among teachers who work in the same area of knowledge, as the support of fellow teachers from the same area provides a horizontal form of professional encouragement.

In addition, the teachers suggested that this support should begin with the planning of the area meetings promoted by the $15^{\text {th }} \mathrm{CRE}$, since the difficulty in planning in a group context is associated with the difficulty of bringing together teachers from the various schools that fall under this Coordination (Field notes, $3^{\text {rd }}$ session). This feature characterizes a different and crosscutting level of support and encouragement in the process of implementing professional collaboration, as it involves individuals who take on different roles in the educational structure.

The support and encouragement established among the teachers who participated in the lesson study fostered their involvement in the process and contributed to their overcoming daily professional difficulties, enabling them to form a collaborative group and develop a reflective approach towards their own practice and the teaching of mathematics:

[The lesson study] brought a spark to our lesson, because otherwise we end up stationary [referring to becoming complacent]. Even in the hustle and bustle of daily life, you[the teacher] are driven, and you do some research. But if you don't have a group [of teachers] to support you and exchange ideas with you throughout the day, this drive loses its force. So, the fact that we [teachers] were in contact all week long, talking and supporting each other was a really positive point [in the lesson study] and gave us more encouragement to work. (Marie, final interview)

Judy, on the other hand, stated that by getting to know the reality of other teachers and receiving support from fellow teachers, she felt more capable and self-confident in her work with the pupils in the classroom. She mentions that the support and encouragement established among the peers in the lesson study contributed to her being able to overcome her own personal and professional insecurities:

Sometimes we feel so inferior [because] it's as if we can't get through to the pupils, it seems that we [as a teacher] are unable to resolve the problem, while there [in the lesson study] we get that support. [The teachers shared their realities]: I've also been through that situation. [...]. So, I think that the support I got has made me feel a lot more confident in my work and has often made me look at the pupil from a different perspective. (Judy, final interview)

In short, in the context of the lesson study, mutual encouragement and support proved to be a feature consisting of two inseparable elements, insofar as encouragement fostered an individual and collective boost for action, while support promoted concrete conditions for the development of the action. In addition, these elements are related biunivocally, since encouragement mobilizes the conditions for action, while the creation of conditions for action encourages teachers to act and take risks, thus attaining professional collaboration.

\section{Cooperation}

Cooperation was achieved through teamwork and contributed to the evolution of the lesson study, to the smooth progress of its stages and to the quality of the tasks developed for the research lesson, thus fostering professional collaboration. The dynamics of the lesson study promoted the voluntary cooperation of the participants in all the stages of the process:

[It was] A different teacher education process to what we were used to, very different. This is what attracted me and made me want to stay and continue on the course... [...] The lesson planning is totally different, there's collective work and everything is decided in a group. We don't make any decisions [alone]. (Ellie, $3^{\text {rd }}$ session)

In the context of discussing a paper that addressed the dynamics of lesson study, Ellie highlighted how the dynamics of planning fostered cooperation among the peers, promoting changes in the attitudes of the participants since they were willing to carry out activities, each doing his/her part. In this cooperative environment, the teachers were open to collaborating and to creating the conditions required for the feasibility of the lesson study. In this regard, Kadu refers to the way in which each participant took on tasks:

When we started [planning the research lesson], [...] the typing up part [of the plan], I said: leave this part to me. I like the area involving technologies, computers and things. So l'd go there [to the computer] and start doing that part [...] They [the fellow teachers] displayed confidence [in me]. Then [during the course of planning] they would point things out and [talk about what needed to be done]. I think I took charge of the part of going there and starting to type [the planning], and doing the research [whatever was needed]. The teachers discussed the lesson plan [and I organised it on the computer] and saved it on the drive. (Kadu, final interview) 
For Kadu, the dynamics of the lesson study made it possible for each teacher, based on their knowledge and preferences, to take on different tasks, which together made the process feasible. Marie says that lesson planning fostered cooperation, while their cooperative attitude intensified the teamwork:

[The lesson planning] was a very different experience, because each one of us was responsible for bringing material, for researching something different, for thinking about a creative situation for the theme of the lesson. Each one of us accepted this without any fellow teacher having to reinforce it. [And when] we presented the class to the group, everyone made the effort to improve the aspects that weren't good enough. (Marie, final interview)

According to Marie, the planning of the research lesson was characterized by cooperation as it enabled the teachers to gradually become involved in the activity and for the groups to develop their tasks with better quality. The tasks carried out cooperatively were organized to be integrated, and this required an additional effort on the part of the participants, strengthening the group work and fostering collaboration. According to Judy,

Everyone tried to help [in something]. I thought this was marvellous. A really good group. I felt so much at home that here at home [referring to her family] they would say to me: well, this course must be good because when Friday comes around, she drops everything and goes. (Judy, final interview)

In Judy's view, cooperation among the teachers fostered good relationships and strengthened the professional ties among peers in the same field who face common challenges. Similarly, Kadu highlighted his impressions of cooperation in the lesson study:

All the teachers were participative. I was one of the younger teachers with less classroom experience. So it was like this, each teacher would give their contribution, and this was really interesting, there was this exchange [among the] teachers with more experience [and] the teachers with less experience. (Kadu, final interview)

Kadu concludes that the effective participation of everyone in the process was fueled by the cooperative attitude of each participant, which permeated the exchange of experiences among the teachers with different levels of experience and culminated in their contribution based on their possibilities.

\section{Shared Reflection}

Shared reflection emerged in the lesson study as a new feature, because the reflective process began in the individual dimension and through the different perspectives of fellow teachers, it became more complex and profound and more and more elements were added. The reflections of the participants throughout the process showed challenges, fears and professional anxieties that teachers usually face alone. These situations, due to an absence of dialogue or shared experiences with fellow teachers, are assimilated and made natural, often becoming professional obstacles, as teachers alone are unable to find solutions to such problems.

From a perspective that is contrary to personal and idiosyncratic reflection, the dynamics of the lesson study enabled teachers to reflect together on classroom teaching, professional practice and the need for change in teaching practice. This experience boosted their ability to reflect from another perspective, namely through shared reflection, since different situations of the practice were discussed, so that collectively causal elements and solutions for those situations were found. Teachers pointed to causes of different classroom challenges and, based on different arguments, proposed and reflected on possible solutions. Some of these solutions were put into practice in the scope of the research lesson and later, thought about on again in the post-class reflection stage.

In view of this context of shared reflection, the teachers stressed the importance of taking the pupils' reality into account during the lesson planning stage:

Our planning, it's based on our pupils' needs. We cannot work with a reality that is not in any way the reality of our pupils. (Ellie, $3^{\text {rd }}$ session)

As far as Ellie is concerned, lesson planning needs to depart from the pupils' specific features and requests, to ensure their learning difficulties are met. In addition, the teachers emphasize that it is also necessary to consider the reality of the school context, and that the reality of the school needs to be previously analysed before introducing possible teaching strategies. From this perspective, the teachers stress that the dynamics of the lesson study enabled them to reflect on teaching strategies, especially when they discussed their own experiences in comparison with those of their fellow teachers who teach classes of the same curriculum component in the region's state schools (Field notes, 4th session).

Within the context of the discussion on the exploratory approach to mathematics teaching that was discussed in several lessons, the teachers reflected on the teaching of mathematics, presenting arguments for the causes of different classroom challenges and, based on these different arguments, proposed and reflected on possible solutions. On highlighting the importance of interpreting mathematical concepts for the teaching and learning processes, Kadu states that:

The right way would be to interpret [the concept]. [...]. The pupil hasn't understood [the context], then these definitions [properties of the concept] need to be specified to later [work on] the formulas. [...] but I think this is a characteristic of the mathematics teacher, he [the teacher] explains it there [the task] and then [he presents] the formula, and immediately wants the calculations [from the pupil] [he is not concerned about whether the pupil has understood the concept or not]. 


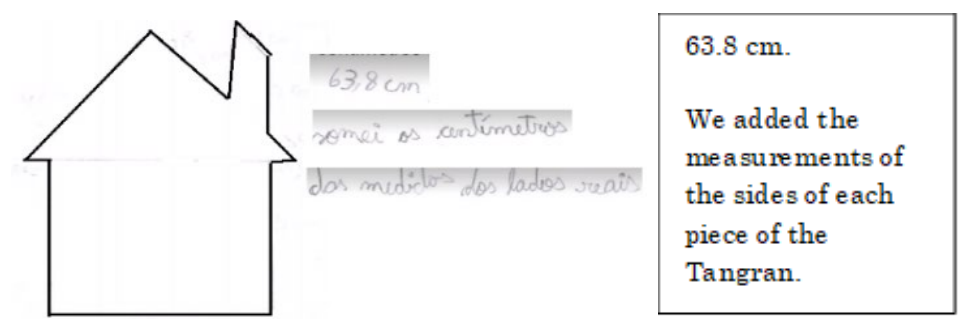

Figure 2. Representation of the outline of musive art

And then, [the pupil] who has just seen the concepts and formulas, no longer knows what is what [referring to the fact that a lack of understanding and interpretation is what leads to the pupils' lack of effective learning]. (Kadu, 10 ${ }^{\text {th }}$ session)

In his analysis of the production of meanings by basic school pupils regarding area and perimeter, Kadu explained the importance of exploring all the mathematical concepts considered essential for learning mathematics. He also highlighted the need to specify and interpret the properties of the elements analysed in the classroom, since a lack of understanding of these properties makes pupil learning difficult. In this context, shared reflection enhanced the proposal of thought out and consistent actions.

In addition to this aspect, shared reflection permeated the lesson planning stage when the teachers considered the 'perimeter and area' topic, reflecting the possibilities of exploring the tangram as concrete material to address this theme. As part of this reflection, they contemplated the importance of providing pupils with the identification and interpretation of the characteristics of each of its constituent geometric figures, such as congruence and vertices, for example, in the basic concepts of these figures (Field notes, $10^{\text {th }}$ session).

On the other hand, Marie, one of the teachers, mentions that the pupils' actions to solve the tasks proposed in the research lessons made it possible for them to observe the strategies they had adopted as well as some of their difficulties. Figure 2 shows this aspect.

The figure illustrates the strategy adopted by a pair of pupils (Assis and Will), who used the planning of musive art to represent the outline, drawing only the external line of the art and informing the total measure. This strategy assumes the notion of integrality of the contour length.

Regarding the strategies of the pupils, Marie emphasizes:

What I found fantastic [was that the pupils] were measuring the sides of the pieces with a ruler, all in centimetres. And the question asked was how many demarcation metres [would be necessary]. [And the pupils] realised that they were working in centimetres, but that they needed metres for the bed. (Marie, $2^{\text {nd }}$ reflection session)

From Marie's perspective, the task led the pupils to realize it was necessary to convert from the centimetre unit of measurement to the meter unit, in such a way that establishing this method of converting units implied understanding what the information was about. In other words, the dynamics of the lesson study promoted reflection on teaching practice, in which Marie highlights the possibility of the mathematics teacher working in articulation with other areas of knowledge:

The question of looking upon the contents as being interrelated, a short while ago you [the teacher] would work on each content in its own box [separately], and a positive feature of this proposal [referring to the exploratory approach proposed by the lesson study] is also the possibility of working on several contents [inter- related] [...] and with other subjects. This also drew my attention because normally we [referring to the teachers] still tend to stick to that approach of not talking in terms of areas. So, this type of proposal also enables this interdisciplinarity of mathematics with other areas of knowledge. (Marie, final interview)

According to Marie, the teacher needs to seek to promote the teaching of mathematical content in an integrated manner, as well as enabling it to be linked to the contents of other subjects, from an interdisciplinary perspective. In addition, Adelle began a reflection on the specific features of the mathematical language used daily by teachers:

We use the wrong mathematical language. When we ask: What is the characteristic of a square? All the sides are the same. No, that's not the characteristic. [The characteristic] is: all the measurements of the sides are the same. [...]. [Another language] two in two, instead of saying two to the power of two. [...]., they [the pupils] understand this part of the mathematical multiplication operation very well. So, minus times minus, plus. What happens here? Here, they [the pupils] take this [idea], and start subtracting and adding, and then that's it [use the rule for multiplication in subtraction]. (Adelle, $1^{\text {st }}$ reflection session)

Adelle argues that the mathematical language used by the teacher, often simplified in order to facilitate pupils' understanding, is inadequate, giving rise to pupils' misunderstanding. Additionally, Ellie stresses that the inappropriate language used in the preparation of the tasks requested of pupils not only hinders their understanding, it also impairs their learning:

We were testing out how we were going to look at the lesson [...] Then, this drew a lot of attention because a word included there [in the question], had several interpretations. And this made me [reflect on] how careful we need to be when we 
propose [design] an activity for pupils, they [the pupils] may have multiple interpretations. So we [teachers] have to be as clear as possible [when designing the activity] [...] । had never stopped to think [about] these other [possible] interpretations, we have one interpretation and want everyone else to have the same, but in reality that's not the case. So we [teachers] must be really careful [in the way] we present an activity to pupils [to ensure they understand what is being proposed]. (Ellie, final interview)

Ellie emphasizes the importance of teachers being attentive to the clarity of the tasks they present to their pupils and concludes that the dynamics of collaborative planning in the lesson study enabled the participants to understand not only this aspect but also many others that go unnoticed in teachers' daily routine. Therefore, the dynamics of the lesson study contributed to the reflection on teaching practice and, consequently, to the professional development of the teachers, as it promoted new perceptions about the teaching of mathematics and the way it is carried out by teachers. Mateus, in turn, emphasizes the need for change in professional practice, especially in terms of the teacher's own planning:

Every year, when the academic year begins, teachers plan the work they expect to accomplish and X lessons to work on specific topics and contents. [In the research lesson, we were able to observe] the extent to which we fail to organize our work accordingly. We fill in [on the schedule] the X lessons required [referring to the timetable of the subject]. So, I start distributing [the contents in accordance with the timetable] to add it all up and close it. But we don't really look at how much is needed [referring to the amount of time required to work on each content]. We were working on area and perimeter [in the research lesson], and we got through three lessons, and didn't finish [we didn't finish the activities] (Mateus, $2^{\text {nd }}$ reflection session).

As far as Mateus is concerned, a change in practice needs to begin at the stage of teachers' general planning to include the time required for each content to be worked on in the classroom, in order to ensure the needs of the pupils are met. It is not simply about being focused on institutional protocols. Likewise, Ellie highlights possible challenges in changing her classroom practice effectively:

I see this [as a teacher] as a huge challenge and a question of patience. Patient to be able to do things [contents] in their time [the pupils] and not in ours. So I [think] that one of the biggest challenges in this type of lesson [research lesson] is having patience, respecting their time [the pupils' time to think]. (Ellie, $1^{\text {st }}$ reflection session)

For Ellie, the biggest challenge for change in practice is the personal process of the ability to respect pupils' learning time, to understand their anxieties and to remain focused on the pupils' learning in the classroom. The reflections promoted by the dynamics of the lesson study, enabled the teachers to look at their teaching practice from a different perspective:

That idea of throwing a question at the pupils and waiting for them to return the answer has really opened my mind to leave that immediate method behind [for example], I [teacher] ask a question and they [pupils] give me an immediate answer. That has changed [in my teaching practice] because the answers I expect of them [pupils] are no longer immediate. (Marie, final interview)

Marie considers that her practice has changed due to participation in the lesson study. Above all, changes have occurred in the teaching strategies adopted in the classroom and in the perspectives of the pupils' actions during the solving of tasks. Similarly, Kadu and Judy have pointed to a change in their own practice because of the lesson study:

The initial lesson plans I was putting together [at the time of the COVID-192 pandemic] [...] I started to think like this: will the pupils understand at home? [So], I first try to put myself [in the position of the pupils and I think] it needs to be something more detailed so the pupils will understand, because they are going to be alone at home, they [pupils] may not have anyone to help [them], ok, we are giving support, they can contact us and clarify their doubts, etc. But, [...] they are going to have to get [the tasks] read and understand them, see what they need to do. [...]. It became more [clear] in the lesson study because we [the teachers] took on the role of the pupils [...]. So, if I put myself [in the position of the pupils] look at the planning that has been done, stop, think, analyse it all [...] and find the things that need to be sorted (Kadu, final interview).

One thing I do a lot of now is to specify as much as possible, being very clear in what I want from them [the pupils], and not something very superficial which for me [the teacher] might be very simple. But from their [the pupils] perspective is far from being simple [...]. So, this has helped me a lot in terms of this aspect, of putting myself in the position of the pupils and considering the doubts that I [as a pupil] might have (Judy, final interview).

The teachers' reports corroborate Marie's reflection insofar as they highlight the change in their own practice, especially in relation to the teaching strategies used in this experience, which were geared towards understanding the pupils. Furthermore, Marie highlights the contribution of the lesson study to her professional growth:

\footnotetext{
${ }^{2}$ COVID-19 is a world health crisis associated with respiratory complications caused by a virus which led the World Health Organisation to declare a pandemic on March 112020.
} 
I hope there are more moments like this, because we grow a lot through these discussions, besides all the content which was totally new to me [...]. Besides the content being a new methodology, these moments of discussion were hugely enriching. You go in one way and come out completely different (Marie, $2^{\text {nd }}$ reflection session).

Therefore, the shared reflection promoted in the lesson study boosted professional collaboration in a different dimension, as it was broadened to the level of beliefs, conceptions, dispositions and the concrete actions of teachers, making individual and collective growth in relation to mathematics education possible.

The main challenge throughout of this process was to overcome the individualism because the professional routine of participant teachers was marked by isolation. The teachers found very strange all aspects of the dynamics of the lesson study. They were very surprised by working collaboratively and through dialogue in the planning of the research lesson, observing classroom teaching and, especially, supporting and encouraging each other. In this perspective, the professional isolation was overcome by mutual support, cooperation, and by shared reflection, which was a new aspect of professional collaboration revealed in our study.

\section{DISCUSSION}

Mutual support, in addition to promoting trust, also fostered the intense and prolonged involvement of the participants in the lesson study (Richit \& Ponte, 2019), since they themselves created the conditions for everyone to participate in the process and encouraged each other to listen and be heard. The encouragement and mutual support experienced in the lesson study contributed to the enhancement of teachers as individuals and the group to which they belong (Borges, 2007), as it served to strengthen the personal and professional relationships among the group members and encouraged them to take on challenging roles and approaches throughout the process.

Moreover, the trust that was established on the basis of support, encouragement and mutual respect created conditions for the teachers to expose their thoughts (Boavida \& Ponte, 2002), expand their knowledge on specific topics (Ponte et al., 2016) and, above all, face and overcome their beliefs, doubts and difficulties. The motivation arising from the support and encouragement among the peers provided a new perspective on professional practice and on the teaching of mathematics, encouraging participants to experiment changes in their practice (Hargreaves, 1998; Guskey, 2002; Lima, 2002), contributing to their personal and professional growth (Day, 2001; Richit \& Ponte, 2019).

Thus, mutual encouragement and support, conceived as intrinsic elements to collaboration, served to stimulate the teachers to confront their challenges, fears, concerns and anxieties during the various lesson study stages. In addition, the good relationship established among the teachers (Boavida \& Ponte, 2002) fostered the development of cognitive and affective aspects of teaching (Saraiva \& Ponte, 2003), strengthened their confidence and ability to overcome difficulties, allowing for different levels of reflection on teaching practice and learning (Lee, 2008).

Mutual support was attained within the group due to the dynamics of the lesson study, which enhanced the commitment of the participants in the collaboration process, in which they developed common goals, provided mutual support (Hargreaves, 1998) and encouraged change. The encouragement and trust that was established among the teachers made it possible for them to achieve these goals, benefiting everyone involved (Boavida \& Ponte, 2002; Lima 2002) as together they embraced the risks and challenges of experimenting a different class on area and perimeter.

Cooperation was a remarkable aspect in the dynamics of the lesson study. Within the scope of planning the research lesson, cooperation made it possible for the teachers to meet the learning needs of different realities, as each group sought to bring different information on the pupils and the resources needed for the activities of each meeting. Furthermore, this dynamic made teamwork possible (Boavida \& Ponte, 2002) and gave rise to the prolonged proximity of the participants (Thurler, 2001) who, despite belonging to the same area of education, worked in school realities that were characterised by different cultural and social features. Thus, the lesson study enhanced professional collaboration, as the teachers cooperated with each other over a long period of time in an activity of common interest, thus strengthening interdependence within the group, the division of responsibilities, collective engagement and the openness to self-assessment and self-criticism (Thurler, 2001).

Cooperation, permeated by the negotiation of ideas and sharing of experiences, made it possible for teachers to experiment a professional activity that surpassed the individualism of the school routine (Hargreaves, 1998; Richit \& Tomkelski, 2020), within a framework of collaborative planning and shared coordination of the process. Thus, collaborative work fostered as each teacher voluntarily performed activities that were closer to their professional competences and interests.

Moreover, the dynamics of the lesson study enabled the teachers to reflect on their practice (Guskey \& Huberman, 1995; Day, 2001; Roldão 2007), the need for changes in professional practice (Ponte et al., 2016), the professional practice in light of the specific cultural features of educational contexts (Richit \& Ponte, 2019; Richit \& Tomkelski, 2020), the difficulties and challenges inherent to educational change (Saraiva \& Ponte, 2003), the moral foundations of teaching and how teachers' actions in the classroom are influenced by all these aspects (Day, 2001; Guskey \& Huberman, 1995) and on teaching objectives and resources (Burroughs \& Luebeck, 2010). The analysis showed, however, that due to the dynamics of the lesson study, reflection transcended the individual dimension to reach a collective dimension, thus characterizing shared reflection.

Shared reflection was initiated by thinking about teaching practice and teaching mathematics in the final years of basic education, about the difficulties of the pupils and the teaching strategies used to address those difficulties. The teachers then reflected on possible reasons for the pupils' difficulties, as well as the importance of promoting tasks that would lead them to take an active role in the classroom. Finally, the participants discussed changes in teaching objectives, strategies and resources to 
promote pupil learning in specific curriculum topics, some of which were incorporated into the research lesson. Thus, by fostering articulated, reflected work, that was thought through jointly, based on the dynamic interaction among the teachers involved (Roldão, 2007) who belonged to the same teaching area (Feixas, 2004), the lesson study contributed to promoting professional collaboration at the level of the participants' beliefs, dispositions and actions.

The reflections carried out from a shared perspective stemming from the socialization of the experiences related to the participants' practices contributed to the proposal of actions and interactions for future practices, leading them to promote changes in their classroom practice (Ponte et al., 2016; Richit \& Ponte, 2019) in their professional beliefs, dispositions and attitudes (Day, 2001). These reflections motivate them to promote changes in the pupils' learning outcomes (Guskey, 1997, 2002), as they defined more coherent teaching objectives and incorporated different strategies and materials into the research lesson, embracing the risks of this challenge.

In short, shared reflection constituted an important dimension of professional collaboration, as it led the participants to reflect on the different aspects that interfere with pupils' learning and to propose strategies and resources to overcome those difficulties. Moreover, the lesson study enabled them to attain different levels of reflection on the teaching and learning of mathematics (Lee, 2008). The participants began by recalling experiences and challenges in the teaching of mathematics in the final years of basic education and reflected on the causes and actions taken to solve teaching problems. They then reflected on those challenges, proposing new ways of confronting them, using new strategies and resources.

\section{CONCLUSION}

The professional collaboration carried out in the lesson study was promoted based on different features that function in articulation with each other. The teachers were given the opportunity to experience a collaborative and reflective form of teacher education, thus overcoming the individualism prevalent in the teaching profession. The analysis highlighted three aspects in particular that are addressed in this paper: mutual encouragement and support, cooperation and shared reflection.

With regard to mutual encouragement and support, the importance of these features is highlighted in the teachers' narratives of facing daily challenges at school, as well as in the development of teamwork. Mutual support and encouragement proved to be inseparable elements, insofar as encouragement provided the boost required for the teacher to make decisions, to question, take risks or experiment changes and the mutual support provided conditions for the teacher to carry out these actions. Thus, we believe that this feature has the potential to promote changes in practice. Mutual support and encouragement established trust among the participants, so that each one felt motivated to become intensely and longly involved in the lesson study and, above all, to face and overcome personal and / or professional difficulties.

Cooperation permeated all the stages of the lesson study, enabling the teachers to experience a collaborative, voluntary and reflective form of planning, so that each contribution was valued in teamwork. The cooperation observed in the group contributed to the progress of the process, as each participant was involved in a voluntary, intense and proactive way in the accomplishment of the different activities that were part of the whole process. In addition, the cooperation promoted by the lesson study contributed to the teachers' realisation that the process materializes as each participant does his/her part.

Shared reflection was also an important element of individual and collective development in the experience under study. The reflections stemming from the dynamics of the lesson study led teachers to think deeply about the teaching and learning processes, and contributed to the reflection on the need for changes in practice.

The lesson study enhanced the relationships among the participants, promoting a sense of belonging to a group that is confronted with similar challenges. In addition, the teachers had the opportunity to experience teacher education focused on teamwork, which fostered the proactive involvement of everyone in the process. The dynamics of the lesson study promoted mutual support and encouragement, cooperation in carrying out tasks and reflection on teaching practice, so that these elements, taken as a whole, promoted collaboration. We note that the way these aspects relate to each other is an issue for further research. In addition, teacher professional collaboration in lesson study may involve other aspects, which may emerge in other contexts. Therefore, more research on this theme is welcome and needed.

Author contributions: All authors have sufficiently contributed to the study, and agreed with the results and conclusions.

Funding: This article received national funding from FCT - Fundação para a Ciência e a Tecnologia, IP, within the SCope of UIDEF - Unidade de Investigação e Desenvolvimento em Educação e Formação (contract UIDB/04107/2020).

Declaration of interest: No conflict of interest is declared by authors.

Acknowledgements: We extend our gratitude to the eight teachers who participated in this lesson study, for their intense engagement in the process and invaluable contribution to this research.

\section{REFERENCES}

Bardin, L. (2003). Análise de conteúdo [Content analysis]. Edições 70.

Boavida, A. M., \& Ponte, J. P. (2002). Investigação colaborativa: Potencialidades e problemas [Collaborative research: Potentials and problems]. In GTI (Ed., Reflectir e investigar sobre a prática profissional (pp. 43-55). APM.

Borges, M. P. A. (2007). Professores: Imagens e auto-imagens [Teachers: Images and self-images] (Doctoral dissertation in Education, Universidade de Lisboa, Faculdade de Ciências). 
Burroughs, E., \& Luebeck, J. (2010). Pre-service teachers in mathematics lesson study. The Montana Mathematics Enthusiast, 7(2/3), 391-400.

Day, C. (1999) Professional development and reflective practice: Purposes, processes and partnerships. Pedagogy, Culture \& Society, 7(2), 221-233. https://doi.org/10.1080/14681369900200057

Day, C. (2001). Desenvolvimento profissional de professores: Os desafios da aprendizagem permanente [Teacher professional development: The challenges of lifelong learning]. Porto Publisher.

Feixas, M. (2004). La influencia de factores personales, institucionales y contextuales en la trayectoria y el desarrollo docente de los profesores universitarios [The influence of personal, institutional and contextual factors on the trajectory and teaching development of university professors]. Educar, 33, 31-59. https://doi.org/10.5565/rev/educar.260

Guskey, T. (1997). Research needs to link professional development and student learning. Journal of Staff Development, 18(2), 3640.

Guskey, T. (2002). Professional development and teacher change. Teachers and Teaching: Theory and Practice, 8(3/4), 381-391. https://doi.org/10.1080/135406002100000512

Guskey, T., \& Huberman, M. (1995). Professional development in education: New paradigms and practices. Teacher College Press.

Hargreaves, A. (1998). Os professores em tempos de mudança [Teachers in times of change]. McGraw-Hill.

Isoda, M. (2007). Una breve historia del estudio de clases de matemáticas en Japón: Dónde comenzó el estudio de clases y qué tan lejos ha llegado [A Brief History of the Study of Mathematics Classes in Japan: Where the Study of Classes Started and How Far It Has Come]. In M. Isoda, A. Arcavi, \& M. A. Lorca (Eds.), El Estudio de Clases Japonés em matemáticas: Su importancia para el mejoramiento de los aprendizajes en el escenario global (pp. 33-39). Ediciones Universitarias de Valparaíso.

Lee, I. (2008). Fostering preservice reflection through response journals. Teacher Education Quarterly, 35(1), 117-139. https://www.jstor.org/stable/i23478939

Lewis, C. (2002). Lesson study: A handbook of teacher-led instructional change. Research for Better Schools.

Lima, J.A. (2002). Culturas colaborativas nas escolas: Estruturas, processos e conteúdos [Collaborative cultures in schools: Structures, processes and contents]. Porto Publisher.

Murata, A. (2011). Introduction: Conceptual overview of lesson study. In L. C. Hart, A. S. Alston, \& A. Murata (Eds.), Lesson study research and practice in mathematics education (pp. 1-12). Springer. https://doi.org/10.1007/978-90-481-9941-9_1

Perrenoud, P. (2002). A prática reflexiva no ofício do professor: Profissionalização e razão pedagógica [Reflective practice in the teacher's profession: Professionalization and pedagogical reason]. Artmed.

Ponte, J. P., Quaresma, M., Mata-Pereira, J., \& Baptista, M. (2016). O estudo de aula como processo de desenvolvimento profissional de professores de matemática [Lesson study as a professional development process for mathematics teachers]. Bolema, 30(56), 868-891. https://doi.org/10.1590/1980-4415v30n56a01

Richit, A. (2020). Estudos de aula na perspectiva de professores formadores [Lesson study from the perspective of teacher educators]. Revista Brasileira de Educação, 25(2), 1-24. https://doi.org/10.1590/s1413-24782020250044

Richit, A., \& Ponte, J. P. (2019). A colaboração profissional em estudos de aula na perspectiva de professores participantes [Professional collaboration in lesson study from the perspective of participating teachers]. BOLEMA, 33(64), $937-962$. https://doi.org/10.1590/1980-4415v33n64a24

Richit, A., \& Ponte, J. P. (2020). Conhecimentos profissionais evidenciados em estudos de aula na perspectiva de professores participantes [Professional knowledge evidenced in lesson study from the perspective of participating teachers]. Educação em Revista, 36(59), 1-29. https://doi.org/10.1590/0102-4698190699

Richit, A., \& Tomkelski, M. L. (2020). Aprendizagens profissionais de professores de matemática do ensino médio no contexto dos estudos de aula [Professional learning of high school mathematics teachers in the context of lesson study]. Acta Scientiae, Revista de Ensino de Ciências e Matemática, 22(3), 2-27.

Richit, A., Ponte, J. P., \& Tomkelski, M. L. (2020). Desenvolvimento da prática colaborativa com professoras dos anos iniciais em um estudo de aula [Development of collaborative practice with teachers from the early years in a lesson study]. Educar em Revista, 36(2/3), 1-24. https://doi.org/10.1590/0104-4060.69346

Richit, A., Ponte, J., \& Tomkelski, M. (2019). Estudos de aula na formação de professores de matemática do ensino médio [Lesson study in the formation of high school mathematics teachers]. Revista Brasileira Estudos Pedagógicos, 100(254), 54-81. https://doi.org/10.24109/2176-6681.rbep.100i254.3961

Roldão, M. C. (2006). Currículo e natureza profissional do conhecimento dos professores: focagem ou difusão? [Curriculum and professional nature of teachers' knowledge: focus or diffusion]. In Actas do Colóquio Luso-brasileiro sobre Questões Curriculares, Braga.

Roldão, M. C. (2007). Colaborar é preciso: Questões de qualidade e eficácia no trabalho dos professores [Collaborating is necessary: Issues of quality and effectiveness in the work of teachers]. Noesis, 71, 24-29.

Saraiva, M., \& Ponte, J. P. (2003). O trabalho colaborativo e o desenvolvimento profissional do professor de Matemática [The collaborative work and professional development of the mathematics teacher]. Quadrante, 12(2), 25-52.

Thurler, M. G. (2001). Inovar no interior da escola [Innovate inside the school]. Artmed. 
Tomasi, A. P. (2020). Aspectos da colaboração profissional docente mobilizados em um estudo de aula no contexto brasileiro [Aspects of professional teaching collaboration mobilized in a classroom study in the Brazilian context] (Master's thesis in Education, Universidade Federal da Fronteira Sul, Chapecó, Brazil). 